\title{
Simultaneous Quantitative Determination of Bupropion and its Metabolites by High Performance Liquid Chromatography Tandem Mass Spectrometry Detection: Application to Bioequivalence Study
}

\author{
Pradeep Kumar Shahi ${ }^{1,2 \star}$, Haresh Patel ${ }^{1}$, Vishal Shah ${ }^{1}$, Ashutosh Bhokari', Rajamannar Thennati ${ }^{1}$, \\ Rakshit Ameta ${ }^{2}$
}

${ }^{1}$ Pharmacokinetics Department, Sun Pharmaceutical Industries Limited, Tandalja, Vadodara, Gujarat, INDIA. ${ }^{2}$ Department of Chemistry, Pacific University, Udaipur, Rajasthan, INDIA.

\begin{abstract}
Objective: A rapid, selective, sensitive, precise and accurate liquid chromatography in tandem with electro-spray ionization mass spectrometry method has been developed and validated for the simultaneous quantification of bupropion (BPR), hydroxyl bupropion (HBPR), erythrohydrobupropion (EHBPR) and threohydrobupropion (THBPR) in human plasma using only $100 \mu \mathrm{L}$ of human plasma sample. Methodology: Multi reaction monitoring detection was performed by electrospray ionization in the positive ion mode, conferring an additional selectivity to the method. The solid phase extraction technique was used for sample preparation. Chromatographic separation of drug and metabolites with better peak shape and resolution was achieved by using an Acquity BEH phenyl column with an isocratic elution of $42 \%$ methanol and $58 \%$ ammonia $(0.06 \%, \mathrm{v} / \mathrm{v})$ aqueous solution at a flow rate of $0.5 \mathrm{ml} / \mathrm{min}$. Methanol was chosen because it enabled good resolution between THBPR and EHBPR as well as good peak symmetry of all the four analytes. Detection was carried out by mass spectrometry using positive electro-spray ionization mode, and the compounds were monitored using multiple reactions monitoring method. Deuterium-labeled isotopes of the compounds were used as internal standards. Results and Conclusion: No significant matrix effect was observed in the presented method. The assay method was validated over the concentration range of $1.75-500 \mathrm{ng} / \mathrm{ml}$ for BPR; $5-1000 \mathrm{ng} / \mathrm{ml}$ for HBPR; 0.5-100 $\mathrm{ng} / \mathrm{ml}$ for EHBPR; and 2-500 $\mathrm{ng} / \mathrm{ml}$ for THBPR as per FDA guideline and validated method was successfully applied for estimation of drug and metabolite concentration in the healthy adult volunteers, bioequivalence and pharmacokinetic study of Bupropion hydrochloride $300 \mathrm{mg}$ extended release tablets under fasting condition.
\end{abstract}

Key words: Simultaneous determination, Liquid chromatography, Mass spectrometry, Bupropion, Metabolites, Plasma, Bioequivalence.

\section{INTRODUCTION}

Bupropion hydrochloride is an antidepressant of the aminoketone class, is chemically unrelated to tricyclic, tetracyclic, selective serotonin re-uptake inhibitor. It is designated as ( \pm )-1-(3-chlorophenyl)-2-[(1, 1-dimethylethyl) amino]-1- 12 propanone hydrochloride. The molecular weight is 276.2 . It is white, crystalline, and highly soluble in water. It is available in $75 \mathrm{mg}$ and $100 \mathrm{mg}$ IR tablets; and 100, 150, 200 and $300 \mathrm{mg}$ in ER tablets. It appears likely that only a small proportion of any orally administered dose reaches the systemic circulation intact as absolute bioavailability is unknown. Plasma
Submission Date: 05-02-18; Revision Date: 17-05-18; Accepted Date: 22-05-18

DOI: 10.5530/ijper.52.4s.74 Correspondence: Mr. Pradeep Kumar Shahi, Pharmacokinetics Department, Sun Pharmaceutical Industries Limited, Tandalja, Vadodara, Gujarat, INDIA. Phone: 91-91-9924314799 E-mail: pradeep.shahi@ sunpharma.com

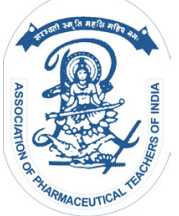

www.ijper.org 
bupropion concentrations are dose-proportional following single doses of 100 to $250 \mathrm{mg}$. Bupropion is extensively metabolized in humans. Three metabolites have been shown to be active: hydroxybupropion, which is formed via hydroxylation of the tert-butyl group of bupropion, and the amino-alcohol isomers threohydrobupropion and erythrohydrobupropion, which are formed via reduction of the carbonyl group. It is indicated for the treatment of depression. Reported $\mathrm{C}_{\max }$ based on Bupropion hydrochloride $100 \mathrm{mg}$ tablets for BPR, HBPR and THBPR are $136.2 \mathrm{ng} / \mathrm{ml}, 269.0 \mathrm{ng} / \mathrm{ml}$ and $88.8 \mathrm{ng} / \mathrm{ml}$, respectively.

Literature reveals that HPLC methods for plasma, ${ }^{1-4}$ stability method for plasma, ${ }^{5}$ metabolite characterization, ${ }^{6-7}$ LC-MS methods for human plasma ${ }^{8-13}$ and rat plasma, ${ }^{14}$ pharmacokinetics analysis in human or rat plasma ${ }^{15-24}$ for bupropion and/its metabolite(s) and LC-MS methods for bupropion with combination ${ }^{25-27}$ are reported. It is noted that reported HPLC methods are not sensitive for the quantification in terminal plasma concentration of bupropion and/or metabolites. The reported methods $^{13,15,19,21,22,24}$ are used for quantification of Bupropion only. While the reported methods ${ }^{4,11,14,17,18}$ are used for quantitation of Bupropion and hydroxyl bupropion from plasma samples and hence are not in accordance to Office of Generic Drug guidance for Bupropion BE study requirement. However, reported LC-MS methods, ${ }^{8-9}$ are used for estimation of bupropion with other three metabolites for plasma, neither used isotope labelled standards as internal standards nor performed incurred sample reanalysis which are current European regulatory requirement. Addition to this, plasma samples were prepared by precipitation method which could lead to the matrix effect, ion suppression and enhancement of analyte signal. The method reported by Xiaoming Wang et al. ${ }^{10}$ were used isotope labelled standards as internal standards for estimation of analyte along with 3 other metabolites. However, biological matrix is differing from the normal plasma i.e. umbilical cord plasma and tissue.

Therefore, the purpose of this present study was to mitigate above challenges and to: (a) develop and validate a novel, a selective and sensitive LC-MS/MS assay method that allows the simultaneous quantification of bupropion and all three metabolites with better chromatography separation using solid phase extraction technique and approximately $90 \%$ recovery. This method is validated with at the LLOQ of about $1.75 \mathrm{ng} / \mathrm{mL}$ for Bupropion, $5.0 \mathrm{ng} / \mathrm{mL}$ for Hydroxy Bupropion, $0.5 \mathrm{ng} / \mathrm{mL}$ for Erythro Hydro Bupropion and $2.0 \mathrm{ng} / \mathrm{mL}$ for Threo Hydro Bupropion (b) applied for pharmacokinetics study for estimation of bupropion and its metabolites in healthy volunteers administered a single $300 \mathrm{mg}$ oral dose of bupropion tablets and (c) high throughput analysis with low plasma volume, low cost and faster delivery of results. Also reproducibility of method is demonstrated during the samples analysis of healthy volunteer bioequivalence study and through incurred sample analysis data.

\section{MATERIALS AND METHODS}

BPR was procured from in-house; HBPR, EHBPR, THBPR, BPR $\mathrm{D}_{9}$ and $\mathrm{HBPR} \mathrm{D}_{6}$ were procured from Clearsynth Labs Limited, Mumbai, India. LC-MS grade methanol from JT Baker (Centre Valley, PA, USA); LCMS grade Ammonia (25\%, v/v) from Merck (Worli, Mumbai, India); LC-MS grade formic acid from Fluka (Germany) and water was produced from Milli-Q water purification system (Millipore Merck, USA) were used. Blank plasma was collected into $\mathrm{K}_{2}$ EDTA tubes from drug-free healthy volunteers, clinical pharmacology unit, Sun Pharmaceutical Industries Limited; Independence Ethics Committee approved these processes.

\section{LC-MS System and Conditions}

Chromatographic separation of drug and metabolites with better peak shape and resolution was achieved by using an Acquity BEH phenyl column with an isocratic elution of $42 \%$ methanol and $58 \%$ ammonia $(0.06 \%$, $\mathrm{v} / \mathrm{v}$ ) aqueous solution at a flow rate of $0.5 \mathrm{ml} / \mathrm{min}$. Separation and detection was done with a Dionex UHPLC (Thermo Scientific, Germany) integrated to API-5500 triple quadrupole mass spectrometer (A B Sciex, Canada). An electrospray ionization technique was used for better sensitivity for all the analytes. The 21 CFR part 11 approved software, analyst version 1.5.1 (A B Sciex, Canada) was used for method setup, data acquisition, and data processing and reporting. Separation of all the analytes was achieved within 6 min run time. Injection volume of only $1 \mu$ l was used to achieve better sensitivity with nil matrix effect and the needle was washed with $100 \mu \mathrm{l}$ of water: methanol (50:50, v/v) between injections to avoid any carry over. The autosampler and column oven temperature was optimized at $6 \pm 2^{\circ} \mathrm{C}$ and $45 \pm 2^{\circ} \mathrm{C}$, respectively.

The MS was operated in positive ionization mode, to achieve the desired area response over the dynamic range. The electrospray voltage was set at $5 \mathrm{kV}$, the source temperature at $450^{\circ} \mathrm{C}$ and dwell time at $0.2 \mathrm{sec}$. The $\mathrm{GS}_{1}$ and $\mathrm{GS}_{2}$ pressures were set of 45 and 60 arbitrary units, respectively. Nitrogen gas was used as the curtain gas which was set at 45 arbitrary units and collision gas was set at 8 arbitrary units. The molecular ion was 
Table 1: Mass spectrometry specification for Bupropion and its metabolites with its internal standards.

\begin{tabular}{|c|c|c|c|c|c|c|}
\hline $\begin{array}{c}\text { Analyte } \\
\text { name\# }\end{array}$ & $\begin{array}{c}\mathbf{Q}_{\mathbf{1}} \\
\text { mass }\end{array}$ & $\begin{array}{c}\mathbf{Q}_{\mathbf{3}} \\
\text { mass }\end{array}$ & DP & EP & CE & CXP \\
\hline BPR & 240.3 & 184.1 & 60 & 10 & 16 & 12 \\
\hline HBPR & 256.3 & 130.0 & 54 & 10 & 61 & 17 \\
\hline \multirow{2}{*}{ EHBPR } & 242.4 & 168.1 & 66 & 10 & 23 & 12 \\
\cline { 3 - 7 } & 186.2 & 66 & 10 & 15 & 14 \\
\hline THBPR $^{2}$ & 242.4 & 168.1 & 65 & 10 & 23 & 12 \\
\hline BPRD $_{9}$ & 249.3 & 185.1 & 62 & 10 & 17 & 13 \\
\hline HBPRD $_{6}$ & 262.3 & 244.3 & 51 & 10 & 17 & 17 \\
\hline
\end{tabular}

\#BPR for Bupropion, HBPR for hydroxyl bupropion, EHBPR for Erythrohydrobupropion, THBPR for Threohydrobupropion, D: deuterium standard used as internal standard.

characterized and selected from $\mathrm{Q}_{1}$ spectra and further fragmented in to $\mathrm{Q}_{2}$ mode and monitored by $\mathrm{Q}_{3}$ mode. The most sensitive mass transitions $(\mathrm{m} / \mathrm{z})$ were monitored in multiple reaction monitoring. Mass spectrometry specification for bupropion and its metabolites with its internal standards are provided in Table 1.

\section{Stock Solutions, Calibration Standards and Quality Controls (QC)}

Stock solutions of all analytes and IS were prepared from their respective reference standards in methanol to achieve the concentration of stock solution of $1 \mathrm{mg} / \mathrm{ml}$ for BPR, EHBPR, THBPR; $2 \mathrm{mg} / \mathrm{ml}$ for HBPR; $0.1 \mathrm{mg} / \mathrm{ml}$ for $\mathrm{BPRD}_{9}$ and $\mathrm{HBPRD}_{6}$. All stock solutions of analyte and IS were stored at $2-8^{\circ} \mathrm{C}$.

\section{Calibration Standards and QC Samples Preparations}

The working solutions of calibration standards and quality control samples for all analytes were prepared in human $\mathrm{K}_{2}$ EDTA plasma which was free of significant interference. The $\mathrm{BPRD}_{9}$ was used as an internal standard for BPR, EHBPR and THBPR however $\mathrm{HBPRD}_{6}$ was used as an internal standard for HBPR.

\section{Sample Pre-Treatment}

The $5 \mu \mathrm{L}$ of working CC/QC solution of analytes were spiked in $95 \mu \mathrm{L}$ of human blank $\mathrm{K}_{2}$ EDTA plasma which were free of significant interference at the retention time (RT) for the transition of analytes and the IS $\left(\mathrm{Q}_{1} / \mathrm{Q}_{3}\right)$. The $25 \mu \mathrm{L}$ of WIS solution $(100 \mathrm{ng} / \mathrm{ml}$ of each of $\mathrm{BPR} \mathrm{D}_{9}$ and $\mathrm{HBPR} \mathrm{D}_{\hat{\theta}}$ ) were added and $200 \mu \mathrm{L}$ of $1 \% \mathrm{v} / \mathrm{v}$ of formic acid in water solution were added and followed by solid phase extraction (SPE) sample processing method using HLB $(30 \mathrm{mg} / 1 \mathrm{cc})$ which were pre-equilibrated with methanol and water. The cartridges were washed with water followed by elution with $250 \mu \mathrm{L}$

\begin{tabular}{|c|c|c|c|c|}
\hline \multirow{2}{*}{ Levels } & \multicolumn{4}{|c|}{ Analyte $\mathrm{Name}^{\#}$} \\
\hline & BPR & HBPR & EHBPR & THBPR \\
\hline $\begin{array}{l}\mathrm{CC} \\
\text { range }\end{array}$ & $1.75-500.69$ & $4.92-983.13$ & $0.501-100.25$ & $2-500.5$ \\
\hline LLOQ & 1.75 & 4.92 & 0.501 & 2.00 \\
\hline LQC A & 5.25 & 13.46 & 1.441 & 5.75 \\
\hline LQC B & 15.74 & 40.37 & 4.323 & 17.25 \\
\hline MQC A & 124.96 & 249.17 & 26.378 & 125.00 \\
\hline MQC B & 227.42 & 438.53 & 44.486 & 225.00 \\
\hline HQC & 387.36 & 772.42 & 78.32 & 387.50 \\
\hline ULOQ & 500.69 & 983.13 & 100.25 & 500.5 \\
\hline
\end{tabular}

\# refer Table 1 for abbreviation of analyte name.

of methanol; two times. The samples were transferred into fresh glass HPLC vial for analysis.

\section{Calibration Curves, Accuracy and Precision and Limit of Quantitation}

A calibration curve consisting of a blank (without drug and without IS), zero blank (without drug and with IS), nine standards in the range and QCs $(\mathrm{n}=7$ separate extractions for each level) stated in Table 2, were prepared and analyzed in a single analytical run. Calibration curves were constructed using a linear regression equation of analyte/IS peak area ratios versus nominal concentrations with a $1 /$ concentration $\mathrm{x}$ concentration weighting. Accuracy was defined as a percentage deviation of measured concentration from the nominal value and precision was defined as the percentage coefficient of variation ( $\% \mathrm{CV})$. Not less than $75 \%$ of all standards and $67 \%$ of all QCs (50\% at each level) in any batch were required to have a percentage deviation within \pm $15 \%$ except LLOQ where a percentage deviation within $\pm 20 \%$.

To determine the lower limit of quantitation and upper limit of quantitation 6 replicates of $\mathrm{CS}_{1}$ and $\mathrm{CS}_{9}$ were analyzed against calibration curve of precision and accuracy (P and A) batch in same analytical run.

\section{Dilution Integrity}

To investigate dilution integrity for clinical samples with concentrations above the reference range, The DQC samples were prepared from $1.5-3$ times of ULOQ concentration by 5 times diluting using interference free blank plasma and these samples were processed and analysed in a single run along with freshly processed calibration standards (CS) and two sets of QC samples. The final concentrations were then derived by backcalculating with the appropriate dilution factor. 


\section{Selectivity, Matrix Effect, Recovery and Carry Over}

Human $\mathrm{K}_{2}$ EDTA plasma from 6 different sources (4 normal +1 hemolysed +1 lipemic) along with LLOQ sample prepared in each lot was analyzed, to determine the interference of an endogenous substance at the RT of all analytes.

To investigate matrix effect, the aqueous samples of LQC-A and HQC samples was prepared by adding $5 \mu \mathrm{L}$ of respective working solution and $25 \mu \mathrm{L}$ WIS in $470 \mu \mathrm{L}$ of methanol, mixed well and transferred to HPLC vials for analysis. The blank human $\mathrm{K}_{2}$ EDTA plasma (4 normal, 1 lipemic and 1 hemolysed) were processed up to elution step as per analytical test procedure. Six vials of each extracted LQC-A and HQC were prepared by adding $5 \mu \mathrm{L}$ of respective working solution, $25 \mu \mathrm{L}$ of WIS in $470 \mu \mathrm{L}$ of processed blank. All these samples were transferred to HPLC vials for analysis.

Relative recovery of all analytes were evaluated by comparing mean analyte responses of six extracted QC samples of LQC-A, MQC-B and HQC level to the six unextracted QC samples at same level. For the IS, mean IS response of eighteen extracted samples was compared to that of the eighteen un-extracted QC samples. Similarly, absolute recovery of all analytes and IS were evaluated by comparing extracted sample to post extracted QC samples at same level. A \%CV of $\leq 15 \%$ across all QC concentrations was set as the level of acceptance for both matrix effect and recovery in line with the FDA guideline.

Carryover test was performed in the sequence of extracted sample of blank (PB), LLOQ, ULOQ, PB, ULOQ, PB, Un-Diluted Quality Control, PB, DQC, PB. The interference in plasma blank was evaluated against LLOQ as reference sample. The carry-over was in- significant if any blank shows more than $20 \%$ response compare to analyte RT and/or more than 5\% response compare to IS RT.

\section{Extended Accuracy and Precision, Ruggedness, and Robustness}

To evaluate accuracy and precision over extended period to cover actual study sample analysis duration, a CS plus a total of 120 spiked QC samples (24 replicates x 5 QC levels) were processed and analyzed in a single analytical run and evaluated as per $\mathrm{P}$ and $\mathrm{A}$ criteria.

The $\mathrm{P}$ and $\mathrm{A}$ experiment was performed with probable changes during study sample analysis like different column with same specification and different analyst. The run consisted of a CS plus a total of 30 spiked QC samples (6 replicates x 5 QC levels) and evaluated as per $\mathrm{P}$ and A criteria.
Robustness QCs with change in buffer volume (i.e. $250 \mu \mathrm{L}$ of $1 \% \mathrm{v} / \mathrm{v}$ formic acid changed from nominal volume of $200 \mu \mathrm{L}$ ) comparison QC sets of 6 samples each at LQC-A and HQC level, CS were processed and analysed in a single analytical run. Comparison QCs (i.e. column oven temperature changed from nominal temperature of $45^{\circ} \mathrm{C}$ to $47^{\circ} \mathrm{C}$ and auto sampler oven temperature changed from nominal temperature of $6^{\circ} \mathrm{C}$ to $8^{\circ} \mathrm{C}$ ) were re-injected as robustness QCs with column oven and auto-sampler temperature change.

\section{Stability and Re-Injection Reproducibility}

All the matrix stability were performed using the bulk spiked samples which were pre-checked (immediately after preparation) for accuracy. Six replicates of bulk spiked LQC-A and HQC samples were subjected for different stability conditions to mimic the study sample analysis condition. These stability samples were processed and analyzed in a single run along with freshly processed calibration standards (CS) and two sets of QC samples. The short term and long term analyte and IS stock as well as working solution for both LLOQ and ULOQ level were evaluated for required storage conditions and durations against freshly prepared stock samples and analyzed in a single run by six replicates injection at each level.

To evaluate the reinjection reproducibility experiment, quality control samples of one $\mathrm{P}$ and $\mathrm{A}$ batch were kept into auto sampler after analysis at $6 \pm 2^{\circ} \mathrm{C}$ and reinjected after $8 \mathrm{~h}$ and evaluated against the acceptance limits of accuracy ( $\pm 15 \%$ of their respective nominal concentration) and precision $(\% \mathrm{CV} \leq 15)$.

\section{Application of Method}

The validated method has been employed for estimation of BPR, HBPR, EHBPR and THBPR concentrations in human volunteer's bioequivalence study under fasting condition, after administration of a single dose ER tablet containing $300 \mathrm{mg}$ bupropion $\mathrm{HCl}$. The study was conducted according to ethic committee and current GCP guideline. There were a total of 27 blood collection time points including the pre-dose samples at 0.0 and post dose samples at $2,3,3.5,4,4.5,5,5.5,6,6.5,7$, $7.5,8,8.5,9,10,11,12,16,24,36,48,72,96,120,144$ and $168 \mathrm{~h}$ time intervals in separate vacationers containing $\mathrm{K}_{2}$ EDTA as an anticoagulant. The plasma from these samples was separated by centrifugation at 3300 rpm at $4 \pm 2^{\circ} \mathrm{C}$ for $15 \mathrm{~m}$ within $1.5 \mathrm{~h}$ after blood sampling collection. These obtained plasma samples were stored at $-20 \pm 5{ }^{\circ} \mathrm{C}$ or colder condition until analysis. The pharmacokinetic parameters were computed using Win-Nonlin ${ }^{\circledR}$ (Pharsight Corporation, version 5.3) using 
non compartmental analyses and 90\% confidence interval was computed using SAS software $\left(\mathrm{SAS}^{\circledR}\right.$ Institute Inc., USA and version 9.2)

\section{RESULTS}

\section{LC-MS Specification}

During the method development, mass parameters, chromatography conditions, mobile phase compositions, extraction conditions were optimized through several trials to achieve better signal to noise level at lower limit of quantitation for all the analytes.

The electrospray ionization (ESI) detection technique has been provided a maximum response over atmospheric pressure chemical ionization (APCI) mode, and was chosen for this method. The instrument was optimized to obtain better sensitivity and signal stability in positive polarity. Maximum response was obtained in positive ion mode as compared to the negative ion mode. The parent ion peaks and product ions in the ESI mode of all analytes with IS were optimized to get maximum sensitivity. The isotopes labeled internal standards were used to compensate loss during sample preparation and avoid the matrix effect during the analysis. The optimized mass transitions and compound dependent parameters of all analytes along with IS were provided in Table 1. The scan width was set at $0.01 \mathrm{~m} / \mathrm{z}$ and the dwell time at $0.2 \mathrm{sec}$.

\section{Chromatography Optimization}

Initially, a different composition of mobile phase with varying combinations was tried with aim to develop the method with better chromatography resolution, better signal and peak shape. Maximum response was achieved with mobile phase containing methanol and ammonia $(0.06 \%, \mathrm{v} / \mathrm{v})$ solution in water. Isocratic mode with different flow rate and composition were tried. The best signal along with a marked improvement in the peak shape was observed for all the analytes using a methanol and the buffer with proportion of $42: 58 \%, \mathrm{v} / \mathrm{v}$ as mobile phase and flow rate of $0.5 \mathrm{ml} /$ minute $(\mathrm{m})$. Different column i.e. Acquity BEH C18 (100 x $2.1 \mathrm{~mm}$, $1.7 \mu$ and $150 \times 2.1 \mathrm{~mm}, 1.7 \mu)$, Acquity BEH C8 (100 x $2.1 \mathrm{~mm}, 1.7 \mu)$, Acquity BEH phenyl $(100 \times 2.1 \mathrm{~mm}, 1.7 \mu)$, Hypurity C18 $(100 \times 2.1 \mathrm{~mm}, 3 \mu)$ and Zorbax XDB C18 $(150 \times 4.6 \mathrm{~mm}, 3.5 \mu)$ were evaluated during the method development but better signal and resolution was achieved with short length column of Acquity BEH phenyl $(100 \times 2.1 \mathrm{~mm}, 1.7 \mu)$. All analytes were eluted within $6.5 \mathrm{~m}$. Also utilization of stable isotope-labeled or suitable analog drugs as an IS was helpful to attain better accuracy and precision over the dynamic range.

\section{Sample Pre-Treatment Optimization}

Start up with different extraction procedures like protein precipitation (PPT), liquid-liquid extraction (LLE) and solid phase extraction (SPE) were tried to obtain better recovery and low matrix effect but ion suppression effect was encountered with protein precipitation method for both the analyte and IS. Hence further method was optimized with SPE and LLE technique and finally concluded that SPE technique was more suitable for extraction of the drug and IS with better recovery and low matrix effect.

Auto sampler wash solution was optimized from 50\% methanol to avoid any carry over effect. The sample volume was selected as $100 \mu \mathrm{L}$ to attain higher level sensitivity for intended application. These optimized detection parameters, chromatographic conditions and extraction procedure resulted in accurate and precise detection of all analytes in human plasma.

Representative chromatograms are shown in Figure 1, with a RT of $3.08 \mathrm{~m}$ for BPR, $1.65 \mathrm{~m}$ for HBPR, 4.23 $\mathrm{m}$ for EHBPR, $4.75 \mathrm{~m}$ for THBPR, $3.01 \mathrm{~m}$ for $\mathrm{BPR}_{9}$, and $1.65 \mathrm{~m}$ for HBPR $\mathrm{D}_{6}$.

\section{Calibration Curves, Accuracy and Precision and Limit of Quantitation}

The method was linear with weighing factor $\left(1 / \mathrm{x}^{2}\right)$ in the range of $1.75-500.69 \mathrm{ng} / \mathrm{ml}$ for BPR; 4.92-983.13

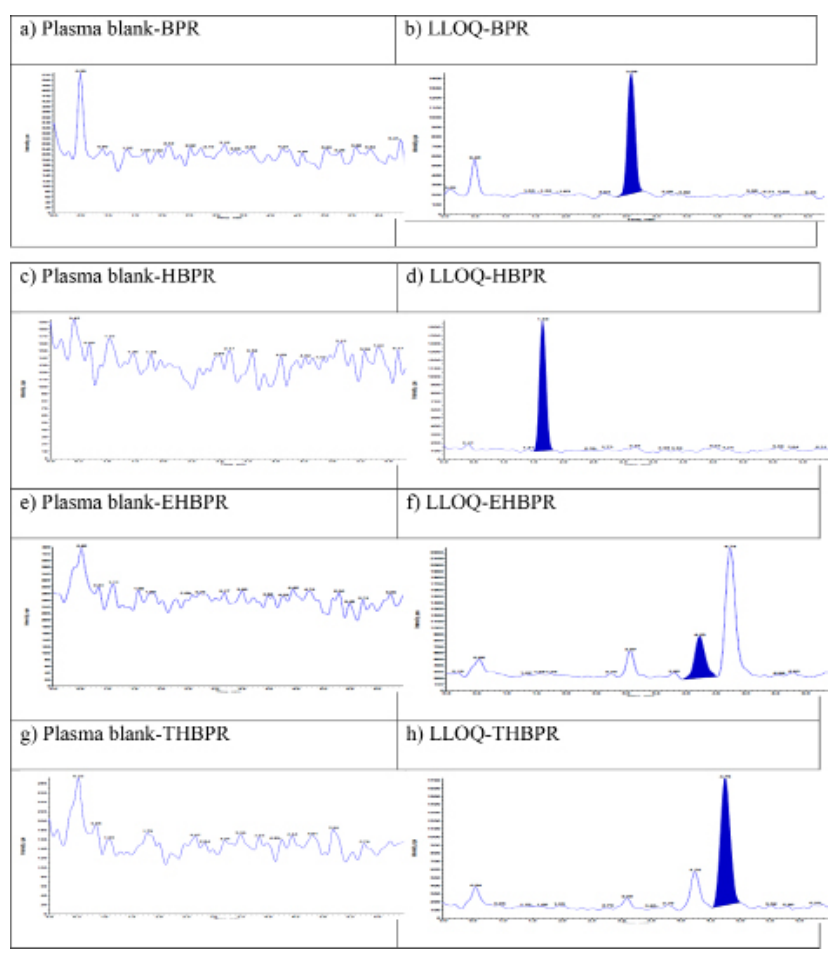

Figure 1: Chromatograms of blank plasma and LLOQ samples of Bupropion and its metabolites. 
Table 3: Intraday and Interday accuracy and precision of Bupropion and its metabolites.

\begin{tabular}{|c|c|c|c|c|}
\hline \multicolumn{5}{|c|}{ Mean (Precision in \%CV) [\%Accuracy] } \\
\hline QC levels (ng/ml) & BPR & HBPR & EHBPR & THBPR \\
\hline \multicolumn{5}{|c|}{ Intraday accuracy and precision } \\
\hline LLOQ & $1.51(6.6)[86.5]$ & $4.47(6.1)[90.8]$ & $0.47(7.3)[93.9]$ & $1.69(5.7)[84.3]$ \\
\hline LQC-A & $4.92(5.8)[93.7]$ & $12.79(6.1)[95]$ & $1.46(6.9)[101.4]$ & $5.55(8.2)[96.4]$ \\
\hline LQC-B & $17.2(5)[109.3]$ & $37.68(5.4)[93.3]$ & $4.34(4.7)[100.5]$ & $16.78(5.7)[97.3]$ \\
\hline MQC-A & $131.64(4.1)[105.3]$ & 253.45(3)[101.7] & $27.63(3)[104.8]$ & $129.74(3.1)[103.8]$ \\
\hline MQC-B & $209.34(2.3)[92]$ & $405.05(2.4)[92.4]$ & $44.47(10.9)[100]$ & $217.26(10.6)[96.6]$ \\
\hline HQC & $371.12(2.6)[95.8]$ & 712.84(3)[92.3] & $75.17(4.1)[96]$ & $365.8(3.8)[94.4]$ \\
\hline ULOQ & $489.48(5.4)[97.8]$ & $946.58(5.6)[96.3]$ & 98.65(5.9)[98.4] & $486.23(5.6)[97.1]$ \\
\hline \multicolumn{5}{|c|}{ Interday accuracy and precision } \\
\hline LLOQ & $1.68(9.9)[95.7]$ & $4.71(7.2)[95.8]$ & $0.48(7.8)[95.9]$ & $1.87(8.3)[93.4]$ \\
\hline LQC-A & $5.25(5.7)[99.9]$ & $13.26(5.2)[98.5]$ & $1.5(6.4)[104]$ & $5.88(6.6)[102.2]$ \\
\hline LQC-B & $17.07(4.1)[108.4]$ & $37.66(4.3)[93.3]$ & $4.28(3.7)[99.1]$ & $16.69(4.1)[96.8]$ \\
\hline MQC-A & $137.97(9.4)[110.4]$ & $266.61(10.8)[107]$ & $28.59(10.5)[108.4]$ & $135.59(11)[108.5]$ \\
\hline MQC-B & $209.62(2.5)[92.2]$ & $408.03(2.2)[93]$ & $42.56(6.4)[95.7]$ & $210.14(6.2)[93.4]$ \\
\hline HQC & $371.63(2.7)[95.9]$ & $722.06(2.9)[93.5]$ & 74.2(3.6)[94.7] & $364.44(3.6)[94]$ \\
\hline ULOQ & 488.77(4.8)[97.6] & 953.31(5.1)[97] & $96.83(5.1)[96.6]$ & $482.09(5)[96.3]$ \\
\hline
\end{tabular}

\begin{tabular}{|c|c|c|c|c|}
\hline \multicolumn{5}{|c|}{ Table 4: Matrix effect and recovery for Bupropion and its metabolites. } \\
\hline \multirow{3}{*}{ Analyte Name } & Level & \%CV of IS-normalized matrix factor & Absolute recovery (\%) & Relative recovery (\%) \\
\hline \multirow{3}{*}{ BPR } & LQC-A & 2.1 & 95.8 & 91.0 \\
\cline { 2 - 5 } & MQC-B & NA & 95.2 & 90.4 \\
\cline { 2 - 5 } & HQC & 1.3 & 95.5 & 90.0 \\
\hline \multirow{3}{*}{ HBPR } & LQC-A & 2.8 & 100.3 & 98.3 \\
\cline { 2 - 5 } & MQC-B & NA & 100.1 & 95.3 \\
\cline { 2 - 5 } & HQC & 1.5 & 99.7 & 94.4 \\
\hline \multirow{3}{*}{ EHBPR } & LQC-A & 3.8 & 97.1 & 96.0 \\
\cline { 2 - 5 } & MQC-B & NA & 100.6 & 96.6 \\
\cline { 2 - 5 } & HQC & 1.3 & 99.5 & 95.5 \\
\hline \multirow{3}{*}{ THBPR } & LQC-A & 1.6 & 98.1 & 96.1 \\
\cline { 2 - 5 } & MQC-B & NA & 100.0 & 96.4 \\
\cline { 2 - 5 } & HQC & 2.0 & 98.9 & 95.4 \\
\hline
\end{tabular}

$\mathrm{ng} / \mathrm{ml}$ for HBPR; $0.501-100.25 \mathrm{ng} / \mathrm{ml}$ for EHBPR; and $2-500.5 \mathrm{ng} / \mathrm{ml}$ for THBPR Intra and inter-day accuracy and precision was well within the acceptance criteria as per FDA and EMA guidelines (Table 3). The mean regression coefficient was $>0.99$ for all analytical run for all analytes.

\section{Dilution Integrity}

The precision and accuracy of DQC samples were found within acceptance criteria. 67\% of QCs samples were in range of $85-115 \%$ with $\% \mathrm{CV} \leq 15 \%$.

\section{Selectivity, Matrix Effect, Recovery and Carry Over}

No significant interference was observed in any lots of plasma samples (normal, lipemic, hemolysed). In addition, zero standards samples were prepared in duplicate from single lot of plasma and were analyzed to determine the interference at RT of respective analyte due to respective IS. No significant interference was observed at the RT of any analytes. \% CV of IS normalized matrix factor for all analytes was found within acceptance criteria and it was below 4\% for both LQC-A and HQC level (Table 4). 
Mean recovery (absolute and relative) values were approximately $\geq 90 \%$ for all analytes and IS, respectively. The difference in $\% \mathrm{CV}$ of recoveries (absolute and relative) across each QC level was within 15\% for all analytes (Table 4). There was no significant injector carry over observed for any of the analyte and IS.

\section{Extended Accuracy and Precision, Ruggedness, and Robustness}

The mean $\%$ nominal value and $\% \mathrm{CV}$ were in range of $85-115 \%$ and less than $15 \%$, respectively across all QC levels for all analytes. This is indicates that method was accurate and precise over extended period and to cover actual study samples analysis time. The $\% \mathrm{CV}, \%$ nominal and $\%$ change of robustness and comparison samples were within acceptance limit with predefined changes in method. The mean $\%$ nominal value and $\% \mathrm{CV}$ were in range of $85-115 \%$ and less than $15 \%$, respectively across all QC levels for all analytes for Robustness experiment.

\section{Stability and Re-Injection Reproducibility}

The concentrations were calculated by the slope and intercept of calibration curve. The mean concentration of plasma stability samples was evaluated in relation with the nominal values and $\% \mathrm{CV}$ were also calculated by mean*100/SD. \%Accuracy for all analytes was found within $85-115 \%$. Hence all analytes were considered to be stable in plasma with defined storage condition and duration. For BT stability in blood, area ratio of stability sample versus freshly prepared samples was compared and $\%$ change was found within $15 \%$ for said storage condition and duration. Similarly for stock solution stability, area response of stability sample versus freshly prepared samples was compared and \% change was found within $10 \%$. The results of matrix stability are provided in Table 5.

For re-injection reproducibility, the $\%$ change of more than $67 \%$ of reinjected QC samples was within $\pm 15 \%$ of back calculated concentration of previously analyzed QC's of P and A batch after $8 \mathrm{~h}$. Hence it was concluded

\begin{tabular}{|c|c|c|c|c|c|}
\hline \multirow{2}{*}{ Stability } & \multirow{2}{*}{ Level } & \multicolumn{4}{|c|}{ Mean $(\% \mathrm{CV})[\%$ accuracy] , (mean concentration in $\mathrm{ng} / \mathrm{ml}$ ) } \\
\hline & & BPR & HBPR & EHBPR & THBPR \\
\hline \multirow{2}{*}{$\begin{array}{c}\text { Bench-top stability plasma } \\
\text { (RT, 6h) }\end{array}$} & LQC-A & $5.16(5.2)[98.3]$ & $13.3(3.3)[98.8]$ & $1.45(3.4)[96.6]$ & $5.9(2.7)[102.1]$ \\
\hline & HQC & $\begin{array}{c}378.61(2.8) \\
{[97.7]}\end{array}$ & $720.8(2.8)[93.3]$ & $73.37(2.8)[94]$ & $366.98(2.9)[94.1]$ \\
\hline \multirow{2}{*}{$\begin{array}{l}\text { Post extraction stability } \\
\text { (RT, } 7 \mathrm{~h})\end{array}$} & LQC-A & $5.27(4)[100.3]$ & $13.26(3.9)[98.5]$ & $1.58(6.6)[105.8]$ & $6.09(4.4)[105.4]$ \\
\hline & HQC & $\begin{array}{c}372.83(2.7) \\
{[96.2]}\end{array}$ & $722.65(2.5)[93.6]$ & $78.87(4.1)[101.1]$ & $373.8(3.3)[95.9]$ \\
\hline \multirow{2}{*}{$\begin{array}{l}\text { Auto sampler stability } \\
\qquad\left(6^{\circ} \mathrm{C}, 96 \mathrm{~h}\right)\end{array}$} & LQC-A & $4.89(4.7)[93.2]$ & $12.98(3)[96.4]$ & $1.52(12.2)[101.4]$ & $6.04(10.8)[104.4]$ \\
\hline & HQC & $\begin{array}{c}392.39(2.7) \\
{[101.3]}\end{array}$ & $744.01(2.9)[96.3]$ & $74.19(5.2)[95.1]$ & $365.52(4.8)[93.8]$ \\
\hline \multirow{2}{*}{$\begin{array}{c}\text { Freeze-thaw stability } \\
\left(-20^{\circ} \mathrm{C}, 4 \text { cycles in water bath }\right)\end{array}$} & LQC-A & $5.04(9.2)[95.9]$ & $12.63(9.1)[93.8]$ & $1.48(9)[98.6]$ & $5.72(9.2)[98.9]$ \\
\hline & HQC & $\begin{array}{c}388.17(2.7) \\
{[100.2]}\end{array}$ & $750.32(1.9)[97.1]$ & $79.02(2.5)[101.3]$ & $392.35(2.6)[100.6]$ \\
\hline \multirow{2}{*}{$\begin{array}{c}\text { Freeze-thaw stability } \\
\left(-35^{\circ} \mathrm{C}, 4 \text { cycles in water bath }\right)\end{array}$} & LQC-A & $5.24(1.9)[99.8]$ & $13.19(2.6)[98]$ & $1.51(1.5)[101]$ & $5.89(4.1)[101.9]$ \\
\hline & $H Q C$ & $\begin{array}{c}392.83(1.2) \\
{[101.4]}\end{array}$ & $758.11(2.4)[98.1]$ & $79.21(1.8)[101.5]$ & $390.29(2.1)[100.1]$ \\
\hline \multirow{2}{*}{$\begin{array}{c}\text { Freeze-thaw stability } \\
\left(-65^{\circ} \mathrm{C}, 4 \text { cycles in water bath }\right)\end{array}$} & LQC-A & $5.41(1.7)[103]$ & $13.16(3)[97.7]$ & $1.52(4.3)[101.8]$ & $5.94(4.7)[102.7]$ \\
\hline & HQC & $\begin{array}{c}386.43(2.2) \\
{[99.8]}\end{array}$ & $747.76(2.1)[96.8]$ & $78(2.9)[99.9]$ & $386.23(3.4)[99.1]$ \\
\hline \multirow{2}{*}{$\begin{array}{l}\text { Long Term plasma stability } \\
\qquad\left(-20^{\circ} \mathrm{C}, 65 \text { Days }\right)\end{array}$} & LQC-A & $5.07(5.1)[96.6]$ & $13.67(4.2)[101.5]$ & $1.48(2.5)[98.8]$ & $5.92(4.2)[102.5]$ \\
\hline & HQC & $\begin{array}{l}386.85(2.9) \\
{[99.9]}\end{array}$ & $752.13(2.7)[97.4]$ & $75.17(6.2)[96.3]$ & $367.13(5.4)[94.2]$ \\
\hline \multirow{2}{*}{$\begin{array}{l}\text { Long Term plasma stability } \\
\qquad\left(-35^{\circ} \mathrm{C}, 65 \text { Days }\right)\end{array}$} & LQC-A & $5.09(5.7)[97]$ & $13.64(3)[101.3]$ & $1.42(6.4)[95.1]$ & $5.8(4.4)[100.3]$ \\
\hline & HQC & $\begin{array}{c}396.39(4.9) \\
{[102.3]}\end{array}$ & $\begin{array}{c}772.98(4.7) \\
{[100.1]}\end{array}$ & $75.56(3.8)[96.8]$ & $371.72(4.6)[95.4]$ \\
\hline \multirow{2}{*}{$\begin{array}{l}\text { Long Term plasma stability } \\
\qquad\left(-65^{\circ} \mathrm{C}, 65 \text { Days }\right)\end{array}$} & LQC-A & $4.97(2.3)[94.6]$ & $13.66(6)[101.5]$ & $1.42(6.4)[95.1]$ & $5.75(4.1)[99.5]$ \\
\hline & HQC & $\begin{array}{c}391.48(3.3) \\
{[101.1]}\end{array}$ & $756.26(2.9)[97.9]$ & $75.56(3.8)[96.8]$ & $363.88(3.5)[93.3]$ \\
\hline
\end{tabular}


Table 6: Mean \pm SD pharmacokinetic parameters of Bupropion and its metabolites in $\mathbf{6 7}$ healthy volunteers after oral administration of Bupropion $\mathrm{HCl} \mathbf{3 0 0} \mathrm{mg}$ ER tablets test and reference products under fasting

\begin{tabular}{|c|c|c|c|c|c|c|c|c|}
\hline \multirow{2}{*}{$\begin{array}{l}\text { Pharmacokinetic } \\
\text { parameters }\end{array}$} & \multicolumn{2}{|c|}{ BPR } & \multicolumn{2}{|c|}{ HBPR } & \multicolumn{2}{|c|}{ EHBPR } & \multicolumn{2}{|c|}{ THBPR } \\
\hline & Test & Reference & Test & Reference & Test & Reference & Test & Reference \\
\hline $\begin{array}{l}\mathrm{AUC}_{0 . \mathrm{t}} \\
\text { (ng.h/ml) }\end{array}$ & $\begin{array}{c}1621.99 \pm \\
562.83\end{array}$ & $\begin{array}{c}1750.9 \pm \\
595.3\end{array}$ & $\begin{array}{c}16468.18 \pm \\
9057.5\end{array}$ & $\begin{array}{c}19071.95 \pm \\
9955.56\end{array}$ & $\begin{array}{l}1687.2 \pm \\
818.29\end{array}$ & $\begin{array}{c}1877.35 \pm \\
765.96\end{array}$ & $\begin{array}{c}10228.47 \pm \\
6658.73\end{array}$ & $\begin{array}{c}11422.39 \pm \\
6956.23\end{array}$ \\
\hline $\begin{array}{l}\mathrm{AUC}_{\text {o-inf }} \\
\text { (ng.h/ml) }\end{array}$ & $\begin{array}{l}1691.5 \pm \\
578.49 \\
\end{array}$ & $\begin{array}{c}1817.89 \pm \\
607.17\end{array}$ & $\begin{array}{c}16792.65 \pm \\
9118.41\end{array}$ & $\begin{array}{c}19464.76 \pm \\
10102.21\end{array}$ & $\begin{array}{c}1736.78 \pm \\
840.6\end{array}$ & $\begin{array}{c}1933.65 \pm \\
794.73\end{array}$ & $\begin{array}{c}10674.9 \pm \\
6938.68\end{array}$ & $\begin{array}{c}11974.32 \pm \\
7376.18\end{array}$ \\
\hline $\mathrm{C}_{\max }(\mathrm{ng} / \mathrm{ml})$ & $\begin{array}{c}136.74 \pm \\
48.95\end{array}$ & $\begin{array}{c}166.73 \pm \\
59.52\end{array}$ & $\begin{array}{c}392.52 \pm \\
187.62\end{array}$ & $\begin{array}{c}457.35 \pm \\
198.49\end{array}$ & $\begin{array}{c}33.72 \pm \\
13.19\end{array}$ & $\begin{array}{c}36.79 \pm \\
12.4\end{array}$ & $\begin{array}{c}228.99 \pm \\
112.89\end{array}$ & $\begin{array}{c}249.85 \pm \\
114.43\end{array}$ \\
\hline$T_{\text {max }}(h)$ & $8.5 \pm 3.12$ & $4.5 \pm 1.76$ & $12 \pm 4.94$ & $11 \pm 5.38$ & $16 \pm 5.97$ & $12 \pm 5.33$ & $12 \pm 3.92$ & $9 \pm 4.38$ \\
\hline $\mathrm{K}_{\mathrm{el}}\left(\mathrm{h}^{-1}\right)$ & $17.71 \pm 6.52$ & $17.39 \pm 6.05$ & $18.46 \pm 3.58$ & $18.95 \pm 3.73$ & $25.62 \pm 5.82$ & $25.86 \pm 6.67$ & $34.88 \pm 7.19$ & $35.89 \pm 8.65$ \\
\hline$t_{1 / 2}(h)$ & $0.05 \pm 0.03$ & $0.05 \pm 0.03$ & $0.04 \pm 0.01$ & $0.04 \pm 0.01$ & $0.03 \pm 0.01$ & $0.03 \pm 0.01$ & $0.02 \pm 0$ & $0.02 \pm 0.01$ \\
\hline
\end{tabular}

\begin{tabular}{|c|c|c|c|c|c|c|c|c|}
\hline \multirow[b]{2}{*}{$\begin{array}{c}\text { PK } \\
\text { Variables }\end{array}$} & \multicolumn{2}{|c|}{ BPR } & \multicolumn{2}{|c|}{ HBPR } & \multicolumn{2}{|c|}{ EHBPR } & \multicolumn{2}{|c|}{ THBPR } \\
\hline & $\begin{array}{l}\text { Ratio of } \\
\text { LSM }^{1}(\%)\end{array}$ & $\begin{array}{c}90 \% \text { Geometric } \\
\text { C.I. }{ }^{2}\end{array}$ & $\begin{array}{l}\text { Ratio of } \\
\operatorname{LSM}^{1}(\%)\end{array}$ & $\begin{array}{c}90 \% \\
\text { Geometric } \\
\text { C.I. }^{2}\end{array}$ & $\begin{array}{c}\text { Ratio } \\
\text { of LSM }{ }^{1} \\
(\%)\end{array}$ & $\begin{array}{c}90 \% \\
\text { Geometric } \\
\text { C.I. }^{2}\end{array}$ & $\begin{array}{l}\text { Ratio of } \\
\operatorname{LSM}^{1}(\%)\end{array}$ & $\begin{array}{c}90 \% \\
\text { Geometric } \\
\text { C.I. }\end{array}$ \\
\hline$A \cup C_{0-t}$ & 92.50 & $79.75-107.30$ & 86.16 & $74.62-99.49$ & 89.71 & $76.77-104.85$ & 89.41 & $76.85-104.01$ \\
\hline $\mathrm{AUC}_{0 \text {-inf }}$ & 92.91 & $80.33-107.47$ & 86.10 & $75.33-98.40$ & 89.68 & $77.48-103.80$ & 89.02 & $76.86-103.10$ \\
\hline $\mathrm{C}_{\max }$ & 81.92 & $73.35-91.49$ & 85.66 & $76.29-96.18$ & 91.50 & $80.88-103.52$ & 91.54 & $80.59-103.97$ \\
\hline
\end{tabular}

${ }^{1}$ Calculated using least square means according to the formula: e(LSM Treatment (A) - LSM Treatment (B)) X 100 ${ }^{2} 90 \%$ Geometric Confidence Interval using In-transformed data.

that any reinjection can be performed during study sample analysis if there is a case of instrument failure.

The validated method has been successfully applied, to quantify analyte and metabolites concentrations in human bioequivalence study under fasting condition, after administration of Bupropion $\mathrm{HCl} 300 \mathrm{mg}$ ER Tablets as an oral dose. The pharmacokinetic parameters evaluated were $\mathrm{C}_{\max }$ (maximum observed drug concentration), $\mathrm{AUC}_{0-\mathrm{t}}$ and $\mathrm{AUC}_{0 \text {-inf }}$ (area under the plasma concentration-time curve measured $t$ time and infinite time, using the trapezoidal rule), tmax (time to observe maximum drug concentration), $\mathrm{K}_{\mathrm{el}}$ (apparent first order terminal rate constant calculated from a semi-log plot of the plasma concentration versus time curve, using the method of the least square regression) and $t_{1 / 2}$ (terminal half-life as determined by the quotient $0.693 / \mathrm{K}_{\mathrm{e}}$ ). Results of pharmacokinetics parameters of bupropion and its metabolites are provided in Table 6.

The plasma concentrations of all analyte and metabolites were used for all pharmacokinetic calculations. Any value below quantification level was considered as zero (0) prior to pharmacokinetics analysis and any subject with pre-dose concentration more than $5 \%$ of their
$\mathrm{C}_{\max }$ was excluded from $\mathrm{BE}$ statistical analysis and the $90 \%$ confidence intervals was calculated based on the remaining subjects.

The Test/Reference ratios for $\mathrm{C}_{\max }, \mathrm{AUC}_{0 \mathrm{t}}$, and $\mathrm{AUC}_{0 \text {-inf }}$ were within $80-125 \%$ for all analytes. The $90 \%$ confidence interval of $\mathrm{C}_{\max }, \mathrm{AUC}_{0-\mathrm{t}}$ and $\mathrm{AUC}_{0 \text {-inf }}$ for $\mathrm{BPR}$ and HBPR are included in Table 7. The mean concentration versus time profile of bupropion and metabolites in human plasma from 67 subjects that are receiving Bupropion $\mathrm{HCl} 300 \mathrm{mg}$ ER Tablets as test and reference is shown in Figure 2. The metabolites data was considered as supportive evidence for comparability of therapeutic outcome of test and reference product.

\section{DISCUSSION}

The proposed bio-analytical method for simultaneous determination of parent drug and its metabolites is sensitive, selective, precise, accurate, rugged and reproducible. This method was successfully applied in bioequivalence study to evaluate the plasma concentrations of parent drug and metabolites in study of healthy human volunteers and study was completed without any 

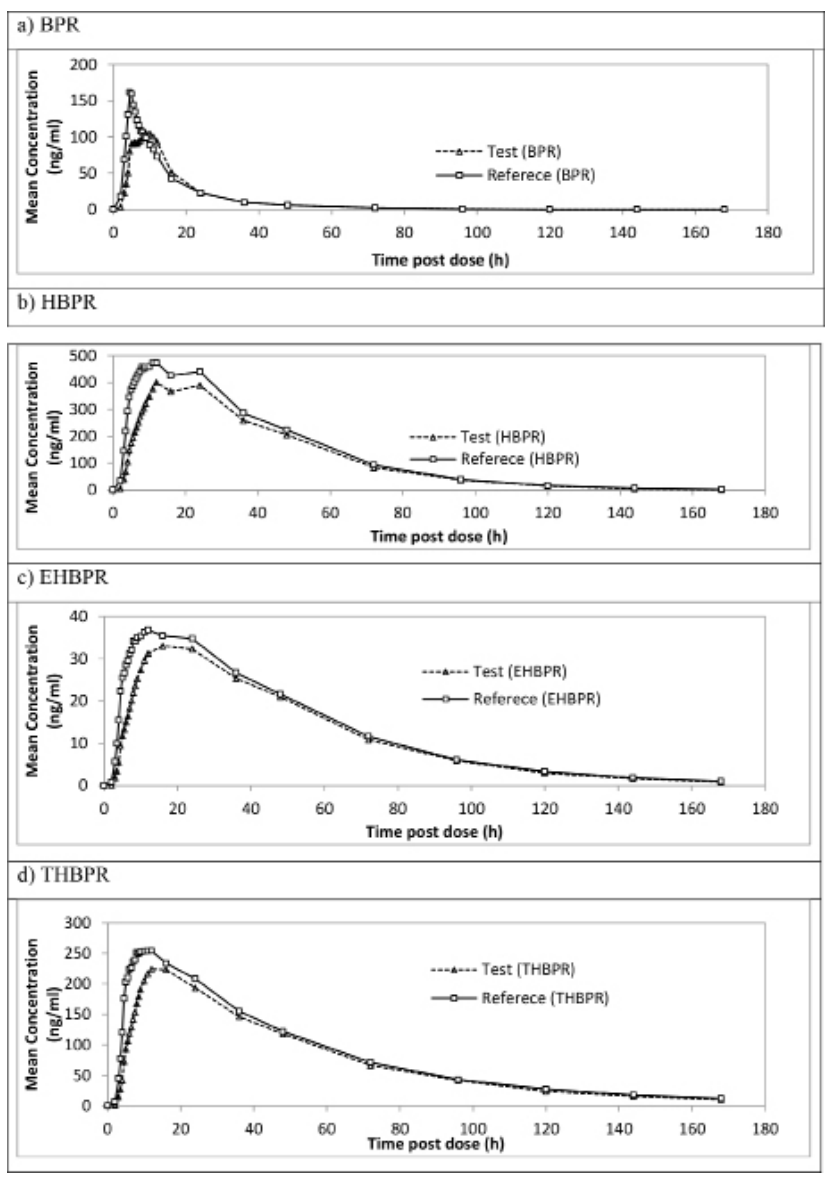

Figure 2: Mean bupropion and its metabolites plasma concentrations of test versus reference after oral administration of $300 \mathrm{mg}$ bupropion $\mathrm{HCl}$ tablets in 67 healthy volunteers.

batch failure. Also incurred sample analysis result was within acceptance for more than $99 \%$ of samples.

\section{ACKNOWLEDGEMENT}

We are thankful to all the colleagues and Sun Pharmaceutical Industries Limited for providing support and carryout research work in Bio-analytical Laboratory. Also special thanks to Dr Rajamannar Thennanti and Dr Rakshit Ameta for providing proper guidance during the execution of research work.

\section{CONFLICT OF INTEREST}

The authors declare no coflict of interest.

\section{ABBREVIATIONS}

BEH: Bridged ethoxy hybrid; FDA: Food and Drug Administration; IR: Immediate Release; ER: Extended Release; Cmax: Maximum plasma concentration; HPLC: High Performance Liquid Chromatography;
USA: United State on America; LCMS: Liquid Chromatography Mass Spectrometry; K2EDTA: Dipotassium Ethylene Diamine Tetra Acetate; BE: Bioequivalence; CFR: Code Federal Regulation; LLOQ: Lower Limit of Quantification; MS: Mass Spectrometry; GS: Gas; DP: Clustering Potential; EP: Entrance Potential; CE: Collision Energy; CXP: Cell Exit Potential; QC: Quality Control, CS: Calibration Standard; WIS: Working Internal Standard; HLB: Hydrophilic Lipophilic Balance; EMA: European Medicines Agency; LQC: Low QC; MQC: Med QC; HQC: High QC; DQC: Diluted QC; ULOQ: Upper Limit of Quantification; PB: Plasma Blank; GCP: Good Clinical Practice, CV: Co-efficient of Variation; SD: Standard Deviation.

\section{REFERENCES}

1. Ulu ST, Tuncel M. Determination of bupropion using liquid chromatography with fluorescence detection in pharmaceutical preparations, human plasma and human urine. Journal of Chromatographic Science. 2012;50(5):433-9.

2. Cooper TB, Suckow RF, Glassman A. Determination of bupropion and its major basic metabolites in plasma by liquid chromatography with dualwavelength ultraviolet detection. Journal of Pharmaceutical Sciences. 1984;73(8):1104-7.

3. Loboz KK, Gross AS, Ray J, McLachlan AJ. HPLC assay for bupropion and its major metabolites in human plasma. Journal of Chromatography. B, Analytical Technologies in the Biomedical and Life Sciences. 2005;823(2):115-21.

4. Lufeng Hu, Zhe Wang, Renai Xu, Jianshe Ma, Xianqin Wang, Xiuhua Zhang. Determination of bupropion and its main metabolite in rat plasma by LC-MS and its application to pharmacokinetics. Pharmazie. 2011;66(12):924-8.

5. Laizure SC, DeVane CL. Stability of bupropion and its major metabolites in human plasma. Therapeutic Drug Monitoring. 1985;7(4):447-50.

6. Connarn JN, Luo R, Windak J, Zhang X, Babiskin A, Kelly M, et al. Identification of non-reported bupropion metabolites in human plasma. Biopharmaceutics and Drug Disposition. 2016;37(9):550-60.

7. Batra S, Bhushan R. Resolution of enantiomers of bupropion and its metabolites by liquid chromatography. Biomedical Chromatography. 2016;30(5):670-82.

8. Teitelbaum AM, Flaker AM, Kharasch ED. Development and validation of a high-throughput stereoselective LC-MS/MS assay for bupropion, hydroxybupropion, erythrohydrobupropion, and threohydrobupropion in human plasma. Journal of Chromatography. B, Analytical Technologies in the Biomedical and Life Sciences. 2016;1017(8):101-13.

9. Masters AR, McCoy M, Jones DR, Desta Z. Stereoselective method to quantify bupropion and its three major metabolites, hydroxybupropion, erythro-dihydrobupropion, and threo-dihydrobupropion using HPLC-MS/MS. Journal of Chromatography. B, Analytical Technologies in the Biomedical and Life Sciences. 2016;201-8.

10. Wang X, Vernikovskaya DI, Abdelrahman DR, Hankins GD, Ahmed MS, Nanovskaya TN. Simultaneous quantitative determination of bupropion and its three major metabolites in human umbilical cord plasma and placental tissue using high-performance liquid chromatography-tandem mass spectrometry. Journal of Pharmaceutical and Biomedical Analysis. 2012;70:320-9.

11. Coles R, Kharasch ED. Stereoselective analysis of bupropion and hydroxybupropion in human plasma and urine by LC/MS/MS. Journal of Chromatography. B, Analytical Technologies in the Biomedical and Life Sciences. 2007;857(1):67-75.

12. Borges V, Yang E, Dunn J, Henion J. High-throughput liquid chromatographytandem mass spectrometry determination of bupropion and its metabolites in human, mouse and rat plasma using a monolithic column. Journal of Chromatography. B, Analytical Technologies in the Biomedical and Life Sciences. 2004;804(2):277-87. 
13. Fogel P, Mamer OA, Chouinard G, Farrell PG. Determination of plasma bupropion and its relationship to therapeutic effect. Biomedical Mass Spectrometry. 1984;11(12):629-32.

14. Yeniceli D, Sener E, Korkmaz OT, Doğrukol-Ak D, Tuncel N. A simple and sensitive LC-ESI-MS (ion trap) method for the determination of bupropion and its major metabolite, hydroxybupropion in rat plasma and brain microdialysates. Talanta. 2011;84(1):19-26.

15. Connarn JN, Flowers S, Kelly M, Luo R, Ward KM, Harrington G, et al. Pharmacokinetics and Pharmacogenomics of Bupropion in Three Different Formulations with Different Release Kinetics in Healthy Human Volunteers. AAPS Journal. 2017;19(5):1513-22.

16. Masters AR, Gufford BT, Lu JB, Metzger IF, Jones DR, Desta Z. Chiral Plasma Pharmacokinetics and Urinary Excretion of Bupropion and Metabolites in Healthy Volunteers. The Journal of Pharmacology and Experimental Therapeutics. 2016;358(2):230-8.

17. Hu L, Wang Z, Xu R, Ma J, Wang X, Zhang X. Determination of bupropion and its main metabolite in rat plasma by LC-MS and its application to pharmacokinetics. Pharmazie. 2011;66(12):924-8.

18. Parekh JM, Sutariya DK, Vaghela RN, Sanyal M, Yadav M, Shrivastav PS. Sensitive, selective and rapid determination of bupropion and its major active metabolite, hydroxybupropion, in human plasma by LC-MS/MS: Application to a bioequivalence study in healthy Indian subjects. Biomedical Chromatography. 2012;26(3):314-26.

19. Daviss WB, Perel JM, Birmaher B, Rudolph GR, Melhem I, Axelson DA, et al. Steady-state clinical pharmacokinetics of bupropion extended-release in youths. Journal of the American Academy Child and Adolescent Psychiatry. 2006;45(12):1503-9.
20. Worrall SP, Almond MK, Dhillon S. Pharmacokinetics of bupropion and its metabolites in haemodialysis patients who smoke. A single dose study. Nephron Clinical Practice. 2004;97(3):c83-9.

21. Zhang D, Yuan B, Qiao M, Li F. HPLC determination and pharmacokinetics of sustained-release bupropion tablets in dogs. Journal of Pharmaceutical and Biomedical Analysis. 2003;33(2):287-93.

22. Stewart JJ, Berkel HJ, Parish RC, Simar MR, Syed A, Bocchini JA, et al. Single-dose pharmacokinetics of bupropion in adolescents: Effects of smoking status and gender. Journal of Clinical Pharmacology. 2001;41(7):770-8.

23. Laizure SC, De Vane CL, Stewart JT, Dommisse CS, LaiAA. Pharmacokinetics of bupropion and its major basic metabolites in normal subjects after a single dose. Clinical Pharmacology and Therapeutics. 1985;38(5):586-9.

24. Lai AA, Schroeder DH. Clinical pharmacokinetics of bupropion: A review. Journal Clinical Psychiatry. 1983;44(5 pt 2):82-4.

25. Ma J, Wang S, Zhang M, Zhang Q, Zhou Y, Lin C, et al. Simultaneous determination of bupropion, metroprolol, midazolam, phenacetin, omeprazole and tolbutamide in rat plasma by UPLC-MS/MS and its application to cytochrome P450 activity study in rats. Biomedical Chromatography. 2015;29(8):1203-12.

26. Park S, Park CS, Lee SJ, Cha B, Cho YA, Song Y, et al. Development and validation of a high-performance liquid chromatography-tandem mass spectrometric method for simultaneous determination of bupropion, quetiapine and escitalopram in human plasma. Biomedical Chromatography. 2015;29(4):612-8.

27. Saracino MA, Marcheselli C, Somaini L, Gerra G, De Stefano F, Pieri MC, et al. Simultaneous determination of disulfiram and bupropion in human plasma of alcohol and nicotine abusers. Analytical and Bioanalytical Chemistry. 2010;398(5):2155-61.

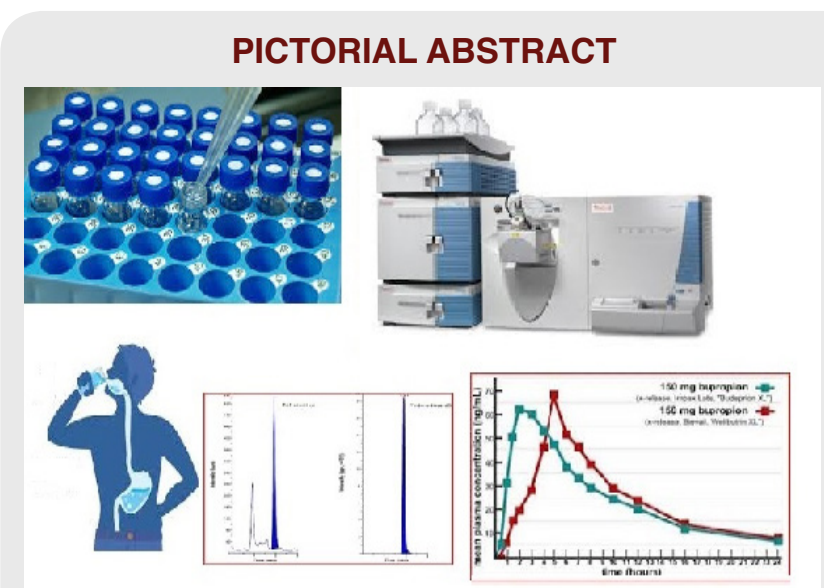

\section{About Authors}

\section{SUMMARY}

- The current study proved that how to develop and to validate a novel, a selective and sensitive LC-MS/MS assay method which allows the simultaneous quantification of bupropion and all three metabolites with better chromatography separation using solid phase extraction technique and required sensitivity.

- The proposed method was satisfied current challenges and regulatory requirements with respect to high throughput analysis with low plasma volume, low cost, faster delivery of results, isotope labelled internal standard, metabolite measurement, and incurred sample analysis data.

- The proposed method was applied for pharmacokinetics study for estimation of bupropion and its metabolites in healthy volunteers administered a single $300 \mathrm{mg}$ oral dose of bupropion tablets.

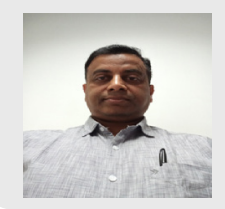

Pradeep Kumar Shahi has industrial experience of 17 years in Bio-analytical and Pharmacokinetics discipline. His research is based on bio-analytical method development for simultaneous determination, Validation and application of a method to bio-equivalence study.

Cite this article: Shahi PK, Patel H, Shah V, Bhokari A, Thennati R, Ameta R. Simultaneous Quantitative Determination of Bupropion and its Metabolites by High Performance Liquid Chromatography Tandem Mass Spectrometry Detection: Application to Bioequivalence Study. Indian J of Pharmaceutical Education and Research. 2018;52(4S):S37-S46. 